\title{
Tasuki Clipping Combined With High Flow Bypass for Ruptured, Previously Coiled, Partially Thrombosed Giant Aneurysm at the Carotid Bifurcation
}

\section{-Case Report-}

\author{
Koji IIHARA, ${ }^{1}$ Daisuke Maruyama, ${ }^{1}$ Kenji FuKUdA, ${ }^{1}$ \\ Norio NAKAJIMA, ${ }^{1}$ and Hiroharu KATAOKA ${ }^{1}$ \\ ${ }^{1}$ Department of Neurosurgery, National Cerebral and Cardiovascular Center, Suita, Osaka
}

\begin{abstract}
A 33-year-old woman presented with a ruptured, partially thrombosed carotid bifurcation aneurysm after partial coiling, which was successfully treated by "tasuki" (a cloth sash crossing from one shoulder to the opposite hip, worn by relay marathon runners) clipping combined with radial artery and external carotid artery-to-middle cerebral artery bypass. "Tasuki" clipping can overcome the dilemma between achieving early complete thrombosis in the blind sac and maintaining anterograde flow of the parent artery to prevent inadvertent occlusion of the perforators and anterior choroidal artery.
\end{abstract}

Key words: giant aneurysm, flow alteration, high flow bypass

Received May 8, 2012; Accepted May 22, 2012 


\section{Introduction}

Partially thrombosed giant aneurysm is an extremely formidable lesion requiring special consideration for management, especially after rupture. Simple clipping is feasible only in exceptional cases and endovascular coiling does not achieve long-term cure, so the optimum treatment strategy should be tailored to each case. ${ }^{1,3,6)}$ Flow alteration or isolation are useful therapeutic options ${ }^{2)}$; but the strategy must consider several critical issues. The most important issue is the prediction of achieving early complete thrombosis after the treatment, especially if the aneurysm is ruptured.5) Another important issue is the fate of critical perforators around the neck of the aneurysm after such treatment. ${ }^{4)}$ Microsurgical management of incompletely coiled aneurysm is another emerging critical issue and various treatment options should be considered to achieve long-term durability of protection from rupture and relief of symptoms, if symptomatic, especially for large or giant aneurysms. ${ }^{9)}$

Here we report a case of ruptured, partially thrombosed carotid bifurcation aneurysm after partial coiling successfully treated by the new technique of "tasuki" (a cloth sash crossing from one shoulder to the opposite hip, worn by relay marathon runners) clipping combined with radial artery and external carotid artery (ECA)-to-middle cerebral artery (MCA) bypass. This case illustrates the dilemma between achieving early complete thrombosis and maintaining antero- or retrograde flow of the parent carotid artery to prevent inadvertent occlusion of the perforators and anterior choroidal artery.

\section{Case Report}

A 33-year-old woman suffered sudden onset of severe headache, with a previous history of recent memory disturbance and mild right hemiparesis for one month prior to presentation. Neuroimaging at the previous hospital had revealed mild bleeding from a partially thrombosed giant aneurysm at the left carotid bifurcation. After partial coiling to prevent rebleeding, she was referred to our institution on day 7. The neurological condition of the patient had almost completely recovered. On admission to our hospital, the mini-mental state examination (MMSE) score was 26.

Magnetic resonance imaging showed a $5 \times 4 \mathrm{~cm}$ irregular-shaped mass in the left frontal lobe appearing as mixed intensity on the $\mathrm{T}_{1}$-weighted image and hyperintensity on the fluid-attenuated inversion recovery image, consistent with perianeurysmal edema (Fig. 1A, B). Cerebral angiography demonstrated an incompletely obliterated, partially thrombosed aneurysm at the left carotid bifurcation (Fig. 1C). The patent lumen was larger on the lateral $\left(\mathrm{M}_{1}\right)$ side, and the packed coils were closer on the medial $\left(A_{1}\right)$ side (Fig. 1D). Manual compression of the left carotid artery showed that the bilateral anterior communicating arteries and posterior communicating arteries (PcomAs) were patent, although the left $\mathrm{A}_{1}$ was relatively small (Fig. $1 \mathrm{E}, \mathrm{F})$.

Although this giant aneurysm was relatively narrow-
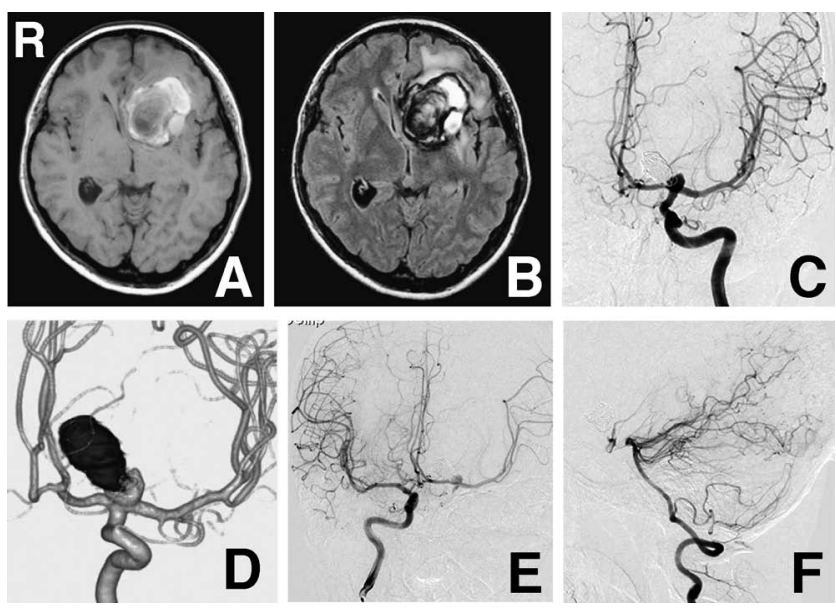

Fig. 1 A, B: Preoperative magnetic resonance images showing an irregular-shaped mass in the left frontal lobe appearing as mixed intensity on the $T_{1}$-weighted image (A) and hyperintensity on the fluid-attenuated inversion recovery image (B). C, D: Cerebral angiograms demonstrating incompletely obliterated, partially thrombosed aneurysm at the left carotid bifurcation (C), the patent lumen larger on the lateral $\left(M_{1}\right)$ side, and the packed coils closer on the medial $\left(A_{1}\right)$ side (D). E, F: Manual compression of the left carotid artery showing the patent bilateral anterior communicating and posterior communicating arteries, with relatively small left $A_{1}$.

necked, direct neck clipping was not considered to be feasible because of the presence of the packed coils and thrombus. Preoperatively, several therapeutic options were planned for flow alteration, as indicated in Fig. 2. Considering the young age of the patient and the relatively small amount of collateral flow, high flow bypass using the radial artery and ECA-to-MCA bypass was preferable for flow alteration. To afford immediate protection from rupture, trapping the aneurysm combined with a bypass was the best option, but the presumed narrow space between the origin of the anterior choroidal artery and carotid bifurcation precluded this possibility. Another option was to form a blind sac from the aneurysm neck by combining proximal carotid clip ligation distal to the anterior choroidal artery and $\mathrm{A}_{1}$ or $\mathrm{M}_{1}$ clipping based on the intraoperative observation of the location of the adjacent perforators. Unfortunately, these options did not seem to be possible either because of the narrow space distal to the anterior choroidal artery. The final option was reverse flow from the high flow bypass down to the PcomA by placing a clip just proximal to the origin of the PcomA. Although this option was possible, the postoperative flow pattern and quantity at the neck of the aneurysm (anterograde versus retrograde flow) was not considered to be predictable, and if this treatment failed, there seemed to be no additional treatment.

Using the left pterional approach with motor evoked potential monitoring, radial artery and ECA-to-MCA $\left(\mathrm{M}_{2}\right.$ inferior trunk) bypass grafting was performed first. Good patency of the bypass was confirmed by indocyanine green (ICG) videoangiography and Doppler ultrasonogra- 

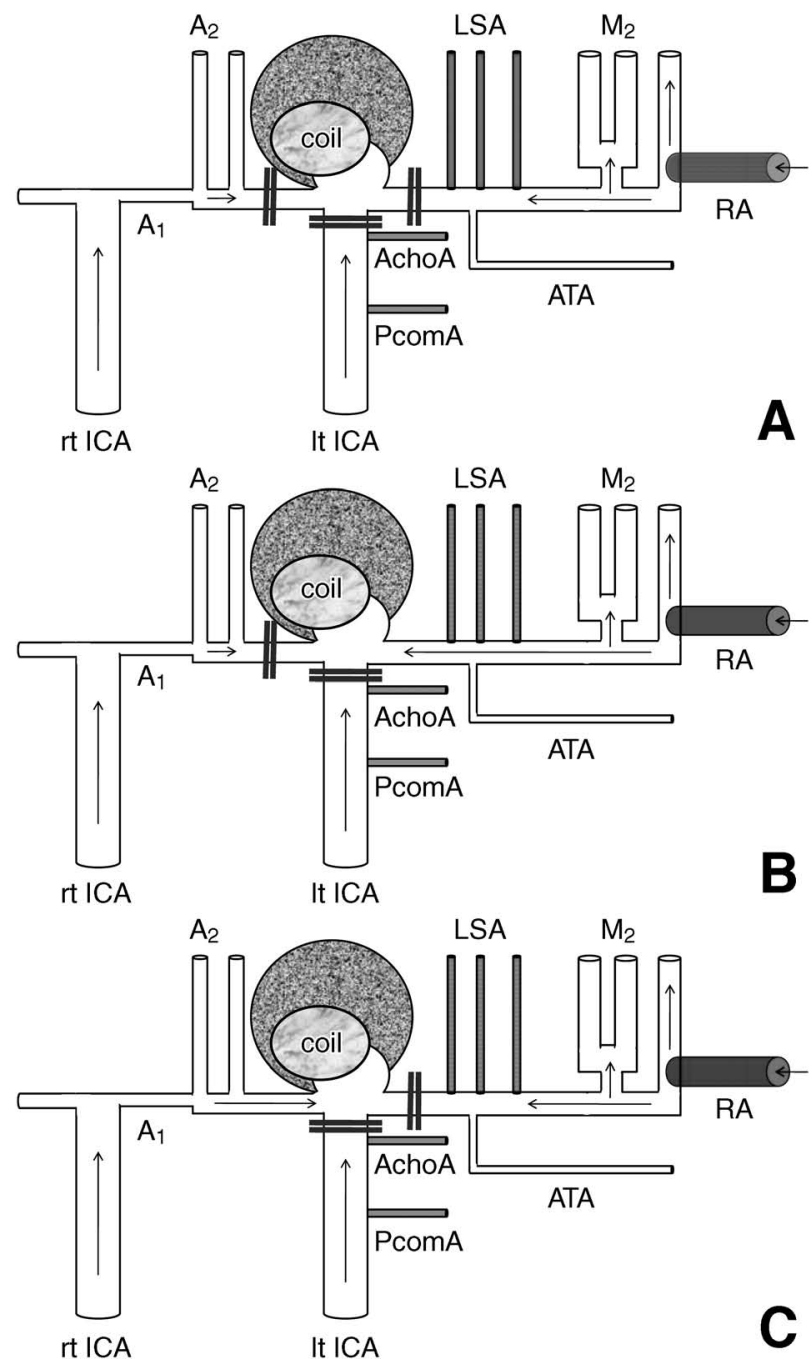

Fig. 2 Therapeutic options considered preoperatively. Trapping with high flow bypass (A), and flow alteration with a combination of high flow bypass with proximal carotid occlusion between the anterior choroidal artery (AchoA) and posterior communicating artery $(\operatorname{Pcom} A)$, and clipping of the proximal $A_{1}$ (B) or $M_{1}$ (C). ATA: anterior temporal artery, ICA: internal carotid artery, LSA: lenticulostriate artery, RA: radial artery.

phy. ${ }^{10)}$ Due to the presence of the giant thrombosed aneurysm embedded in the frontal lobe, only the neck of the aneurysm was exposed even after wide sylvian dissection. Proximal clip ligation between the origin of the anterior choroidal artery and carotid bifurcation was attempted first, but patency of the anterior choroidal artery was not confirmed on ICG videoangiography as expected. Since the neck of the aneurysm seemed to be narrow relative to the huge mass, direct neck clipping was attempted next, but the presence of the coil mass, especially on the medial side, caused slippage of the clip and kinking of the carotid bifurcation. Finally, a titanium bayonet clip was stably placed from the neck on the lateral $\left(\mathrm{M}_{1}\right)$ side (shoulder), crossing the carotid bifurcation, to the medial wall of the carotid artery just proximal to its bifurcation (opposite

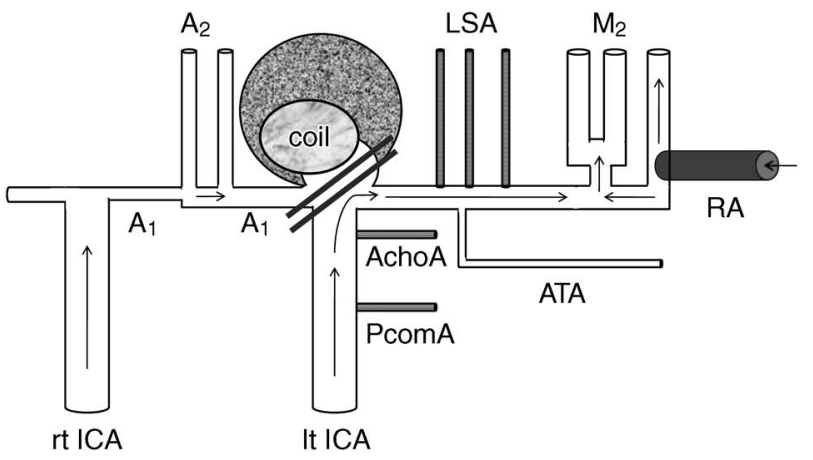

Fig. 3 Therapeutic design of "tasuki" clipping. AchoA: anterior choroidal artery, ATA: anterior temporal artery, ICA: internal carotid artery, LSA: lenticulostriate artery, PcomA: posterior communicating artery, RA: radial artery.

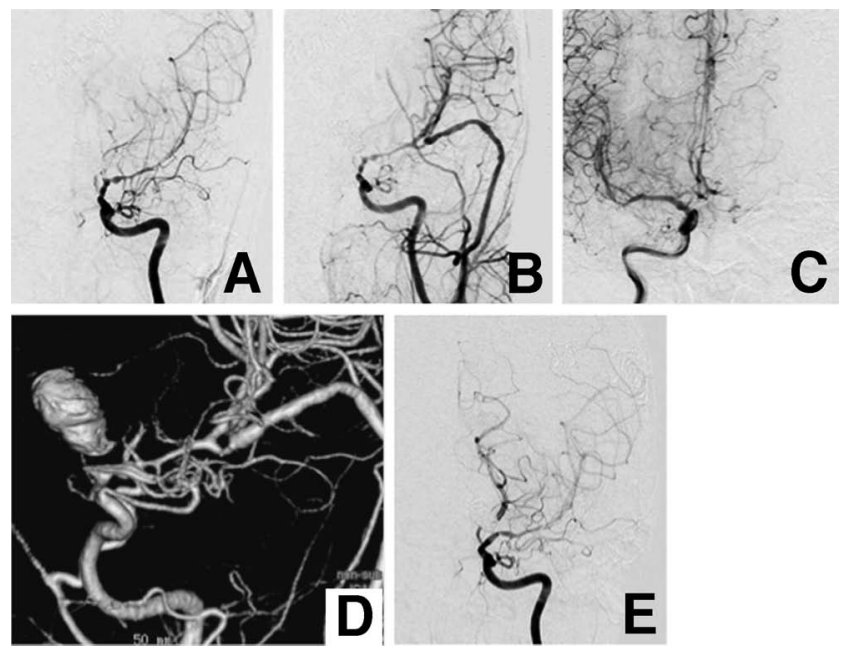

Fig. 4 A, B: Postoperative left internal carotid (A) and common carotid (B) angiograms showing complete obliteration of the aneurysm, sparing of anterograde flow through the mildly narrowed proximal $M_{1}$, and good patency of the high flow bypass. Both anterior choroidal and lenticulostriate arteries are well visualized. C: Right internal carotid angiogram showing partial filling of the left $A_{1}$ segment. D: Three-dimensional rotational digital angiogram showing no residual filling of the aneurysm. E: Digital subtraction left internal carotid angiogram demonstrating mild narrowing of the proximal $M_{1}$ had markedly improved, and complete obliteration of the aneurysm.

hip) (Fig. 3). ICG videoangiography and intraoperative angiography showed anterograde filling of the $M_{1}$ segment with moderate stenosis and good filling of the anterior choroidal artery and adjacent perforators (Fig. 4). Contralateral carotid angiography showed filling of the bilateral anterior cerebral arteries and retrograde filling to the midportion of the left $A_{1}$. The aneurysm was completely obliterated.

The postoperative course was uneventful and her MMSE score returned to normal on postoperative day 8. 
Postoperative angiography on postoperative day 10 confirmed complete obliteration of the aneurysm and maintenance of anterograde filling of the MCA.

\section{Discussion}

The authors have coined the term "tasuki," a Japanese word meaning a cloth sash, crossing from one shoulder to the opposite hip, worn by relay marathon runners, to describe the present clipping technique to achieve complete obliteration of partially thrombosed giant aneurysm and prevent inadvertent occlusion of adjacent critical arteries by sparing anterograde flow of the parent artery to one of the branches. This is a variant form of treatment for such unclippable lesions, especially after rupture, between direct neck clipping and flow alteration to overcome the two incompatible strategies of immediate protection from rupture and sparing antero- or retrograde flow to prevent inadvertent occlusion of adjacent critical perforators and the anterior choroidal artery. The core concept of this treatment is oblique insertion of the clip from the neck on the side with a wider patent lumen toward the distal end of the parent artery on the side where packed coils or intraluminal thrombus encroach closer to the neck. The distal branch incorporated by the clip may not be completely obliterated but only squeezed by the clip such that the residual small aneurysm orifice left in the blind sac may quickly become thrombosed.

Partially thrombosed aneurysms often present with symptoms related to the mass effect, but may rupture to cause fatal subarachnoid hemorrhage. For temporary prevention of rerupture, rescue partial embolization is a possible option, although the durability is low because of distal migration of packed coils caused by the water-hammer effect. ${ }^{2,3)}$ Direct clipping and thrombectomy, and clip reconstruction of partially thrombosed aneurysms are performed in $32 \%$ and $26 \%$ of cases, respectively, but the feasibility seems to be lower after partial embolization. ${ }^{9)}$ Our previous study reported the response to flow alteration treatment for a partially thrombosed large or giant aneurysm in the posterior circulation after multimodality treatment. ${ }^{5}$ Inadvertent occlusion of critical brainstem perforators and branches, such as the anterior choroidal and lenticulostriate arteries, is one of the most serious complications associated with flow alteration or isolation treatment. ${ }^{8)}$ Perioperative use of antiplatelets should be considered based on the patient age and the degree of atherosclerotic change around the aneurysms.

Tasuki clipping is designed for unclippable aneurysms to combine immediate protection from rupture and sparing antero- or retrograde flow to prevent inadvertent occlusion of adjacent critical perforators and important arteries such as the anterior choroidal artery. The direction of the clip insertion requires meticulous attention to achieve this end. Repositioning of the clip may be necessary based on intraoperative observation of the flow pattern. The branch with preserved anterograde flow should be chosen based on the branching angle between the parent artery and the branches. Sparing the anterograde flow may be more easily achieved if the branching angle is obtuse, as for the $M_{1}$ in the present case. If the antero- or retrograde flow is very stagnant as a result of kinking, especially if the parent artery is atherosclerotic, this procedure may be complicated with delayed occlusion of the parent artery and distal migration of the thrombus, and this strategy may be abandoned. In the present case, the terminal carotid artery and origin of the $\mathrm{M}_{1}$ segment showed good anterograde flow despite mild narrowing, and the patient was treated with cilostazol considering the lower risk of hemorrhagic complications. ${ }^{7)}$ Intraoperative angiography showed the aneurysm was completely obliterated. Intraoperative ICG videoangiography showed good patency of the proximal $\mathrm{M}_{1}$ segment, but flow direction in this segment was not confirmed clearly, probably due to turbulence. Further study is necessary to confirm the safety and efficacy of "tasuki" clipping for unclippable aneurysms and to determine the applicability of this technique to a broader range of unclippable aneurysms than partially thrombosed giant aneurysms and aneurysms persisting after partial coiling.

\section{Conflicts of Interest Disclosure}

The authors have no personal financial or institutional interest in any of the drugs, materials, or devices in the article. All authors who are members of The Japan Neurosurgical Society (JNS) have registered online Self-reported COI Disclosure Statement Forms through the website for JNS members.

\section{References}

1) Debrun GM, Aletich VA, Kehrli P, Misra M, Ausman JI, Charbel F: Selection of cerebral aneurysms for treatment using Guglielmi detachable coils: the preliminary University of Illinois at Chicago experience. Neurosurgery 43: 1281-1297, 1998

2) Drake CG, Peerless SJ, Ferguson GG: Hunterian proximal arterial occlusion for giant aneurysms of the carotid circulation. J Neurosurg 81: 656-665, 1994

3) Ferns SP, Majoie CB, Sluzewski M, van Rooij WJ: Late adverse events in coiled ruptured aneurysms with incomplete occlusion at 6-month angiographic follow-up. AJNR Am J Neuroradiol 31: 464-469, 2010

4) Horowitz MB, Yonas H, Jungreis C, Hung TK: Management of a giant middle cerebral artery fusiform serpentine aneurysm with distal clip application and retrograde thrombosis: case report and review of the literature. Surg Neurol 41: 221-225, 1994

5) Iihara K, Murao K, Yamada N, Takahashi JC, Nakajima N, Satow T, Hishikawa T, Nagata I, Miyamoto S: Growth potential and response to multimodality treatment of partially thrombosed large or giant aneurysms in the posterior circulation. Neurosurgery 63: 832-844, 2008

6) Lawton MT, Quinones-Hinojosa A, Chang EF, Yu T: Thrombotic intracranial aneurysms: classification scheme and management strategies in 68 patients. Neurosurgery 56: 441-454, 2005

7) Shinohara Y, Katayama Y, Uchiyama S, Yamaguchi T, Handa S, Matsuoka K, Ohashi Y, Tanahashi N, Yamamoto H, Genka C, Kitagawa Y, Kusuoka H, Nishimaru K, Tsushima M, Koretsune Y, Sawada T, Hamada C: Cilostazol for 
prevention of secondary stroke (CSPS 2): an aspirin-controlled, double-blind, randomised non-inferiority trial. Lancet Neurol 9: 959-968, 2010

8) Steinberg GK, Drake CG, Peerless SJ: Deliberate basilar or vertebral artery occlusion in the treatment of intracranial aneurysms. Immediate results and long-term outcome in 201 patients. J Neurosurg 79: 161-173, 1993

9) Waldron JS, Halbach VV, Lawton MT: Microsurgical management of incompletely coiled and recurrent aneurysms: trends, techniques, and observations on coil extrusion. Neurosurgery 64(5 Suppl 2): 301-317, 2009
10) Woitzik J, Horn P, Vajkoczy P, Schmiedek P: Intraoperative control of extracranial-intracranial bypass patency by nearinfrared indocyanine green videoangiography. J Neurosurg 102: 692-698, 2005

Address reprint requests to: Koji Iihara, MD, PhD, Department of Neurosurgery, National Cerebral and Cardiovascular Center, 5-7-1 Fujishiro-dai, Suita, Osaka 565-8565, Japan. e-mail: kiihara@hsp.ncvc.go.jp 